\title{
Dialectical Methods and Means in the Teaching of Probability and Statistics
}

\author{
Xiaonan Xiao \\ Xiamen University Tan Kah Kee College \\ Zhangzhou, Fujian, China \\ xiaoxn@xujc.com
}

\begin{abstract}
Based on the teaching practice of probability and statistics, this paper probes into the dialectical methods and means in the teaching of probability and statistics, explores how to further strengthen the interactive and practical teaching, also discusses how to cultivate the students' dialectical creative thinking and comprehensive innovation ability.
\end{abstract}

Keywords-probability and statistics teaching; dialectical methods and means; dialectical innovative thinking; comprehensive innovation ability

\section{INTRODUCTION}

Probability statistics is an important applied mathematics subject to study random phenomena and their laws. With the development of science and technology, the application of probability and statistics is becoming more and more extensive, especially in economic management, engineering technology and scientific decision-making.

It is a leap from determining mathematics to random mathematics. Because of the abstractness of probability and statistics, it is difficult for students to begin to accept probability and statistics. It is difficult to understand the basic concepts of probability and statistics. So the basic methods are difficult for students to master. In order to overcome this disadvantage and make the students master this subject better, in the teaching, we have adopted the teaching principle of "grasping the basic, the key point, the difficulty and the application" as well as a series of teaching methods and means. Therefore remarkable teaching effects have been obtained.

\section{Pay Close Attention to The Foundation, and Talk DEEPLY ABOUT THE TwO BASIC CONCEPTS OF "EvENT" AND "PROBABILITY"}

\section{A. Explain the concept of "event" through two main lines.}

(1). The study of random phenomena - pass random trials the result of random events (that is, an event with a certain statistical regularity in a large number of repeated trials).

(2). Simple events (basic events) - generalized to compound events (event operation) - generalize to complex events (general events).

The first line introduces that the essence of events is the result of random experiments. Therefore, events are often expressed as "appearing", "not appearing" or "occurring" and "not happening".
The second main line introduces the relationship and operation of an event. The process of compounding simple events into general events is called the operation of events. Through the practice of an instance, the student can master a given random phenomenon and can use events and related operations to express the problems to be studied.

\section{B. Explain the concept of "probability" in two stages}

(1).First describe the definition of the probability: The number used to indicate the probability of occurrence of event $A$ is called the probability of the event $A$, denoted as $P(A)$. The description exposes the nature of probability. But we cannot use this definition to calculate the probability of an event.

(2).Then focus on the statistical definition and classical definition of probability. And through a lot of practices, students will be proficient in calculating the probability of the event.

\section{Explanation of several commonly used formulas on probability calculation}

In order to make the students master the addition formula, multiplication formula, full probability formula and Bayes formula, we explain the meaning and the method of the above four formulas through some examples that can help the students easy to understand. Through this way, it also further deepens the students' understanding of the above four formulas [1-2].

\section{Emphasis Should Be Placed on Students' Mastery of THE CONTENTS F RANDOM VARIABLES AND NUMERICAL FEATURES}

First, in order to study the random phenomena in depth, we should quantify each result (event) of the experiment, which means that the random variable $\xi$ is the function of the event. So using any real number $x,\{\xi<x\}$ to represent an event, the concept of distribution function (ordinary real function) $F(x)=P\{\xi<x\}$ is derived. In this way, the study of random events can be transformed into the study of random variables, so that we can study random events by means of mathematical analysis, such as calculus, and bring probability statistics into the study of ordinary real functions. It can be said that the introduction of random variables is a milestone in the study of probability and statistics. It makes a great step forward in the study of probability and statistics [3]. 
According to the long-term teaching experience, it is not difficult for students to understand the distribution and digital characteristics of random variables after clarifying the above concepts. However, it should be noted that we should use some typical examples and exercises in this part of the content, so that the students can thoroughly master and use these knowledge.

\section{Overcome Difficulties Implement Them and Solve Practical Problems}

The purpose of probability and statistics is to enable students to use probability and statistics to solve practical problems and build a solid foundation for learning follow-up courses. In order to achieve this goal, trainings to strengthen students' basic skills are an important part. In the course of teaching, we conduct in-depth analysis on some typical and ambiguous examples according to the characteristics that it is difficult for the students to solve problems and the exercises in probability statistics are complex and diverse. In this way, students can open their ideas and they learn to analyze the basic methods of solving problems. Analysis shows that mathematical statistics is both difficult and easy. "Difficult" is due to the limitation of time and foundation. The relevant theories of this part cannot be introduced in detail. Therefore, the students cannot understand some contents and feel difficult. "Easy" is as long as the teachers' pay attention to the methods and teach clearly. The formulas and methods of probability and statistics are static. As long as they are done according to the requirements and steps, we can draw a conclusion and solve the problems. Therefore, in teaching, we should try our best to transform from "difficult" to "easy". For further analysis, we find that it is difficult to export on normal distribution, $\chi^{2}$ distribution, $t$ distribution and $F$ distribution. But what we use is not the deduction of the above distribution, but only the relevant calculation of the relevant conclusions and appellate distribution. The calculation of the above distribution is not difficult. Therefore, when teaching mathematical statistics, it is very important to focus on the four kinds of distributions mentioned above. Table look-up calculation is very important [4-5]. Among them, more attention should be paid to the calculation of normal distribution.

For normal distribution, we pay special attention to explaining and practicing the following two questions:

$$
\begin{aligned}
\text { 1. Standardization: if } \quad \xi \sim N\left(\mu, \sigma^{2}\right), & \text { then } \\
\frac{\xi-\mu}{\sigma} \sim N(0,1) ; &
\end{aligned}
$$

2. If $\eta \sim N\left(\mu, \sigma^{2}\right)$, with the help of the distribution function value of the standard normal distribution, the look-up table calculation for $P\{\eta>\lambda\}=\alpha$ and $P\{|\eta|<\lambda\}=1-\alpha$ : Known $\alpha$,check look-up Table for $\lambda$; Known $\lambda$, check look-up table for $\alpha$.

For $t$ distribution, $\chi^{2}$ distribution and $F$ distribution, the look-up table calculation is basically the same as the normal distribution. The difference is that the normal distribution and the $t$ distribution are symmetrical, and the $\chi^{2}$ distribution and $F$ distribution are asymmetric, so there is a slight difference in the look-up table.

After familiarizing with the above distributions, we will explain the commonly used mathematical statistics methods and then students will easily understand it.

\section{Teaching Effect Has Been Significantly Improved After Reforming Teaching Methods and Teaching MEANS}

In the long-term teaching, we continue to explore and reform teaching methods and teaching methods. We count on students as the main part, teachers as the guide, and teaching as the main route. We teach students in accordance with their aptitude and provide them various teaching methods and methods[6]. A significant teaching effect has been achieved.

\section{A. In practice, we have adopted the following teaching methods.}

(1).Teaching example: From an example, draw out the relevant concepts and theories, and stimulate the students' interest in learning and desire. Let the students understand the basic concepts accurately and deeply.

(2).Interactive teaching: Count on students as the main part and teachers as the guide. Explore the ideas of solving problems. Make the students pay attention to their studies through interactive behavior. Boost the students' learning initiative. Improve the teaching effect.

(3).Heuristic teaching: The essence is to stimulate the students to think independently, to inspire the students to analyze the problems, to guide the students to step by step, to grasp the key. And then eventually the problems are solved.

(4).Discussion teaching: Discuss the cooperative learning among students. Enlighten and guide each other. Teachers should regard themselves as a member of the whole class. They should communicate with students equally and guide their students to express their views. During the discussion each student is not only a person who raises questions, but also a person to solve the problem. It can boost the students' learning initiative and improve the students' ability to study independently.

(5).Problem-based teaching: Pay attention to the introduction of the problem. Teach the students how to analyze the problem and then grasp the essence of the problem. Simplify the complexity. Then the confidence of the students will be built up. The using of recalling questioning, comprehension questioning, and application questioning in the teaching process greatly guide students to think actively

(6).Refining and more practice: In class, focus on the knowledge network, the key point, the difficulty solving, the way of thinking and the method discovering. Insist the principle of "less teaching" and "more learning". Encourage that students learn from practices. Cultivate the students' selfstudy ability. Carefully select examples and after-school exercises, so that students will improve their ability to use the knowledge they have learned to solve practical problems. 


\section{CONCLUSION}

(7).Hierarchical teaching: Respecting the personality of the students. Because of the uneven level of students, under the circumstances of various methods, we set high standards and high requirements for the advanced students to prepare the graduate admission entrance examination. We set low standards and basic requirements for the students who are left behind. And then guide them to smoothly graduate from school.

(8).Innovative teaching: Introduce new knowledge, new methods and new ideas. Integrate the characteristics of foreign teaching and teaching materials into our program. Give probability modeling ideas. Combine analogy, induction, divergence, reverse, and other innovative thinking modes with the content of teaching materials, so that students can establish ideas and methods of stochastic theory and stochastic analysis. Thus students will greatly develop the ability to use and innovate knowledge.

(9).Practical teaching: Combine theory with practice. Encourage students to participate in the contests of mathematical modeling. Improve students' practical ability to solve problems. Instruct students to take an active part in extracurricular innovation and scientific and technological activities. Guide them to select some innovative topics according to their own ability for doing research.

\section{$B$. In the teaching of probability and statistics, we have adopted the following teaching methods}

(1).The application of multimedia teaching technology: Fully utilize the advantages of multimedia. By using interactive, situational, virtualization, and other large amount of information, the classroom atmosphere is improved and the students' interest is enhanced. Thus more examples are introduced, and the practicability of the probability system is vividly embodied. Because of the specific situation of the course of probability and statistics and the way of students' learning, we adopt a combination of traditional and modern teaching methods. The practice shows that the teaching effect is remarkable and the students love it.

(2).The use of computer software technology: Introduce students the common statistical software SPSS, Excel, EVIEW, SAS, MATLAB, etc. Arrange the students to do preliminary mathematical experiments and complete the work on computer. Improve the students' hands-on ability and the ability to use software to process data.

(3).The use of network technology: We use a variety of teaching resources on the Internet, such as electronic courseware, homework answers, questions and answers, syllabus and progress, references and bibliographies, electronic tutoring books, postgraduate examination materials, common domestic and foreign teaching websites and so on. Thus we are discovering a new way of learning for our students. Knowledge that is not understood in class can continue to be learned on the course website by students. Thus it opens up the vision of students, stimulates students' interest in learning, and improves students' autonomous learning ability. Also the online service of answering questions provides a platform for online communication between teachers and students.
In conclusion, the key to further deepening the teaching reform of probability statistics is that the teaching of probability and statistics must be combined closely with the theory and practice. We must constantly strengthen the organic integration of the students' knowledge and application, help to develop the students' knowledge view, and strengthen the innovation, practicality and applicability of the teaching of probability and statistics. Only in this way, the teaching of probability and statistics will be welcomed by students. Then it will meet the needs of the current development of knowledge economy in our country. Finally it will build the necessary mathematical foundation and provide the necessary mathematical tools for the follow-up courses.

\section{REFERENCES}

[1] Zhong Bing Lin. The reform of talent training mode is the core of the connotation construction of advanced education[J]. Chinese University Teaching, 2013,(11)71-76.

[2] Xiao Xiaonan. Micro-thinking and macro development in university mathematics teaching [J].Chinese University Teaching, 2013,(7)

[3] Zhong Bing Lin. Promoting the integration of science and education in universities and striving to cultivate innovative talents [J].China University Teaching,2012,(5):6

[4] Lu Gen Shu. Classroom learning environment, learning style and development of college students[J]. Fudan University Education BBS, 2012,(4):46-55

[5] Zou Xiaodong. Innovation in Science and Engineering Education: Strategies, Patterns and Countermeasures[M].Beijing Science Press,2010.

[6] Gao Youhua. A Study on the Theory of New Higher Education Courses[M]. Zhenjiang; Jiangsu University Press, 2009. 